\title{
INFLUENCE OF THICKNESS AND GRANULOMETRIC COMPOSITION OF GRANULAR ASPHALT ON ITS STRENGTH CHARACTERISTICS WHEN PLACING INTO THE ROAD PAVEMENT
}

\author{
Ekaterina Gennadievna Pakhomova ${ }^{1 *}$, Konstantin Andrianov², Anatoly Zubkov ${ }^{2}$, Pavel Monastyrev ${ }^{2}$ \\ 1 Southwest State University, Kursk, Russian Federation \\ ${ }^{2}$ Tambov State Technical University, Tambov, Russian Federation
}

When performing roadway replacement and reconstruction works, the removal of the road surface by self-propelled road milling machine is provided. The material obtained during milling (granular asphalt) is used in the base layers and lower layers of the coating, provided that the strength requirements are met. The effectiveness of the applied technology in the construction of structural layers of road pavement depends on considering the properties of the used material and the parameters of the mechanic means during works. We have reviewed the influence of the granulometric composition and the granular asphalt layer thickness on its strength properties in the construction of road structures. On the basis of experimental studies, analytical dependences are obtained for calculating the deformation and compacting factor under the action of the compaction loading of used granular asphalt. We have obtained the results to calculate the deformation-stress relationship and the dependence of the compacting factor on deformation, taking into account the granulometric composition and layer thickness. That allows to justify the parameters of compacting machines to ensure the required quality of compacting of the granular asphalt layer.

Key words: granular asphalt, compacting, stress, deformation

\section{INTRODUCTION}

When constructing structural layers of road pavement, the effectiveness of the applied technology depends on considering the properties of the used material and the parameters of the mechanic means when performing works. To ensure the required strength of the structural layer, compacting equipment is used. It is characterized by a wide range of parameters. Achieving the required compacting quality of the material depends on the compliance of the equipment parameters with its strength characteristics $[1,22,23]$.

Currently, $97 \%$ of the total length of roads is covered by roads with non-rigid pavement. When performing roadway replacement and reconstruction works it is planned to remove the road surface. It is performed by self-propelled road milling machines. The material obtained during milling (granular asphalt) is used to prepare hotmixed asphalt, to strengthen road borders, to provide spur roads and for other purposes. It is found that when milling the road surface with a width of 7-7.5 $\mathrm{m}$ to a depth of $0.05 \mathrm{~m}$, about $500-650$ tons of waste are obtained from one kilometer of the road. That significantly allows to reduce the cost of materials when performing works.

Normative documents SRC (sector road code) 218.3.0392003 and CS (code specification) 78.13330.2012 define the areas of granular asphalt application. With appropriate processing, granular asphalt is used in the base and lower layers of the coating, provided that the strength requirements are met. The addition of a binding material (emulsified bitumen or cement) into the granular asphalt helps to increase the tensile strength of the layer from 0.5 to $2.0 \mathrm{MPa}$. Granular asphalt without additives is used in the construction of motor roads of the $4^{\text {th }}$ category with a compressive strength of $0.7 \mathrm{MPa}$, as well as when gutting the upper layer of crushed stone base. Depending on the application, it is deposited in layers of different thickness and grain-size classification, which affects the strength characteristics of the layer and the choice of parameters of compacting equipment in order to achieve the required strength of the road structure.

The normative document CS 78.13330.2012 defines the parameters of the road rollers used for compaction of granular asphalt: it should be pneumatic tired rollers weighing at least 16 tons at a pressure in tires of 0.6$0.8 \mathrm{MPa}$; trailed vibrating rollers weighing at least 6 tons; grid rollers weighing not less than 15 tons; self-propelled rollers with smooth rollers weighing at least 10 tons and combined rollers weighing more than 16 tons. An analysis of the recommended parameters of the rollers shows that they belong to a heavy roller group used at the final stage of the material compacting. At the initial stage of compacting, the use of such rollers leads to the development of plastic deformations, which characterizes the process of destruction of the placed material layer. Therefore, to improve the quality of the compacting and achieve the required strength during the equipment working process, it is necessary to ensure that the stresses under the working object of the machine correspond to the properties of the material being compacted [1] - [3].

Determining the layer parameters (granulometric composition and thickness) of the used granular asphalt which influence on its strength characteristics allows to select the link of machines to achieve the desired quality 
of compacting. Depending on the method of the material placement, the granulometric composition and thickness of the layer, its ability to resist external load will be different, that must be taken into account when choosing the parameters of the compacting machine link. Therefore, in order to ensure the required quality of compacting of granular asphalt layers, it is necessary to specify the influence of the granulometric composition and layer thickness when placing on the choice of the roller parameters.

\section{MATERIALS AND METHODS}

To determine the influence of the granulometric composition and thickness of the granular asphalt layer on its strength and stress-related characteristics during compacting, a preliminary division of the total weight of the material into fractions sizing 5-10, 10-20, 5-20 and 20$40 \mathrm{~mm}$ was carried out. Each fraction of a given thickness was placed into the form of a testing bench with a preliminary compacting and its further post compaction. After completing the specified number of passes with the set load, the compaction coefficient was measured. Itwas determined by a non-destructive method using the ACD -1 (asphaltic concrete density) device. The study was conducted at the CRT-RC-H2 testing bench (Fig. 1). The principle of operation of the testing bench is based on the simulating the operation of the roller by rolling the cylinder sector with a controlled force on the surface of the sample placed into the form of the testing bench. The dimensions of the form for placing the material are $305 \times 400 \mathrm{~mm}$. The completion of a task occurs when the specified number of cycles is performed. The research was carried out in accordance with the methodology set out in the regulatory document DNS 185-2016 (draft national standard) (EN 12697-33).

\section{RESULTS}

Ensuring the required strength of the placed layer depends on the strength characteristics of the granular asphalt, structural layers during placement and compact- ing technology. Depending on the design solution when laying the material, the layer thickness can bedifferent. It was proved that the thickness of the layer affects the stress limit of the laid material, which must be taken into account when choosing compacting machines [4] - [6]. Based on the results of the studies, the strength limits of the placing layer of granular asphalt from its thickness are established. The results are presented in Table 1.

Table 1: Strength limits of granular asphalt depending on its composition and thickness during the placement

\begin{tabular}{|c|c|c|c|c|c|}
\hline \multirow{2}{*}{$\begin{array}{c}\text { No. } \\
\text { of fraction }\end{array}$} & \multirow{2}{*}{$\begin{array}{c}\text { Fraction, } \\
\mathrm{mm}\end{array}$} & \multicolumn{4}{|c|}{ Thickness of a layer, $\mathrm{m}$} \\
\cline { 3 - 6 } & & 0,05 & 0,10 & 0,15 & 0,20 \\
\hline 1 & $5-10$ & 1,7 & 1,6 & 1,5 & 1,4 \\
\hline 2 & $10-20$ & 2,0 & 1,85 & 1,7 & 1,6 \\
\hline 3 & $5-20$ & 2,2 & 2,0 & 1,9 & 1,8 \\
\hline 4 & $20-40$ & 2,3 & 2,1 & 2,0 & 1,9 \\
\hline
\end{tabular}

From the presented data it is seen that the strength limit depends both on the granulometric composition of the granular asphalt and the thickness of the placed layer. As the fraction size increases, the strength limit increases, which is explained by the change in the structure of the layer material during compacting. As an example, Fig. 2 shows the dependence of the strength limit on the granulometric composition for a layer with a thickness of 0.05 .

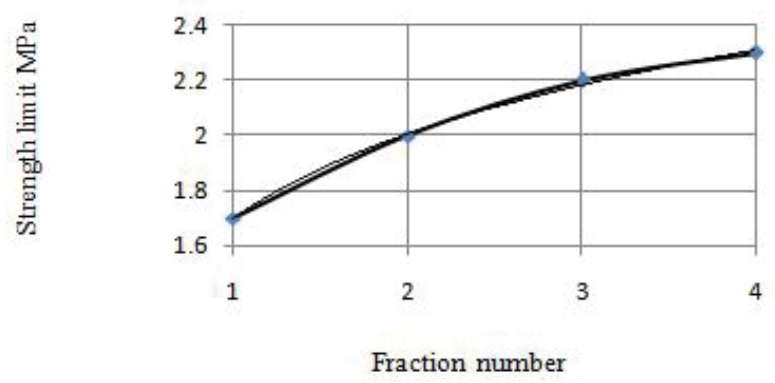

Figure 2: Dependence of the strength limit of granular asphalt layer $0.05 \mathrm{~m}$ thick on the granulometric composition

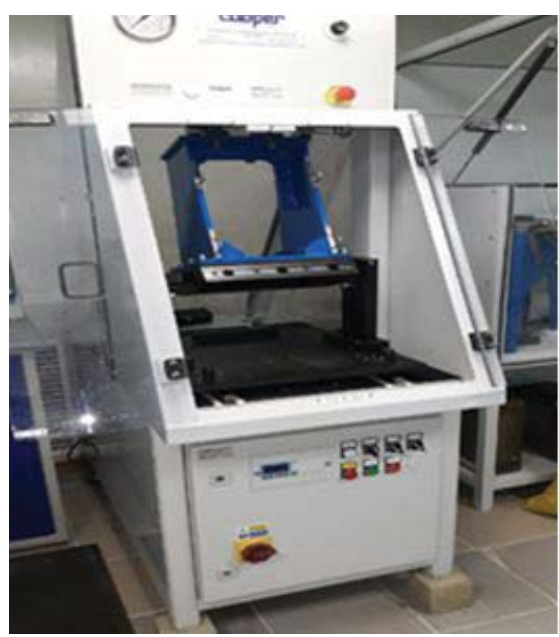

a)

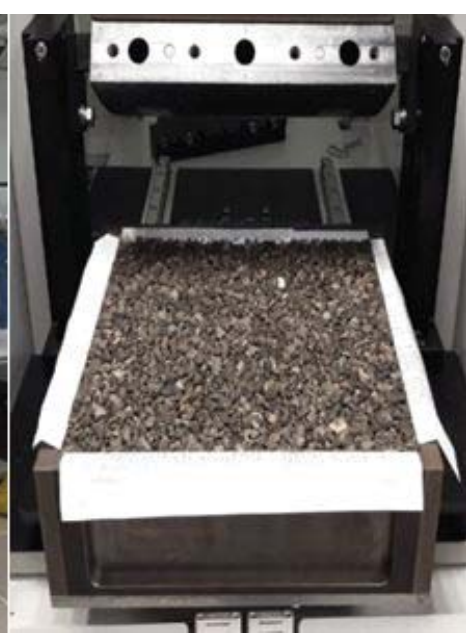

b)

Figure 1: General view of the testing bench (a) and the form to place the material during the test (b) 
The numerical value of the strength limit of the granular asphalt layer for a fraction of $5-10 \mathrm{~mm}$ is determined by the formula:

$$
\sigma_{\mathrm{pr}}=0.439 \operatorname{lnN}+1.7, \mathrm{MPa}
$$

where $\mathrm{N}$ is the fraction number. The correlation coefficient of the equation is 0.99 .

To establish the common pattern of the influence of the granulometric composition of granular asphalt on the strength limit, we present the data from Table. 1 in a form of relative values, assuming the strength limit of each layer at a thickness equal to $0.05 \mathrm{~m}$ per unit (Table 2 ).

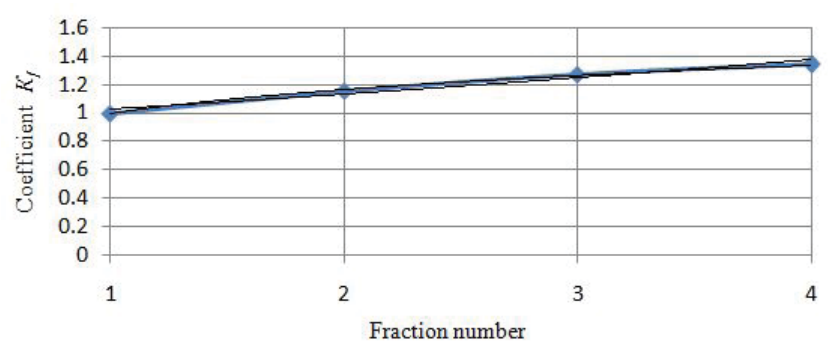

Figure 3: Dependence of the influence coefficient of granulometric composition on the strength limit of granular asphalt layer

Table 2: The influence of the granulometric composition of granular asphalt on the strength limit at different layer thickness (in relative values)

\begin{tabular}{|c|c|c|c|c|c|c|}
\hline \multirow{2}{*}{ Fraction number } & \multirow{2}{*}{ Fraction sizing $[\mathrm{mm}]$} & \multicolumn{4}{|c|}{ Layer thickness when placing [m] } & \multirow{2}{*}{$\sum n / n$} \\
\cline { 3 - 6 } & & 0,05 & 0,10 & 0,15 & 0,20 & \\
\hline 1 & $5-10$ & 1,0 & 1,0 & 1,0 & 1,0 & 1,0 \\
\hline 2 & $10-20$ & 1,176 & 1,156 & 1,333 & 1,142 & 1,151 \\
\hline 3 & $5-20$ & 1,294 & 1,250 & 1,266 & 1,286 & 1,274 \\
\hline 4 & $20-40$ & 1,353 & 1,313 & 1,333 & 1,357 & 1,339 \\
\hline
\end{tabular}

The data of Table 2 demonstrate that the granulometric composition of granular asphalt, independently of the layer thickness, affects the strength limit. Let us denote the accepted value by the influence coefficient of granulometric composition on the strength limit of granular asphalt -Kf (Fig. 3).

The numerical value of the influence coefficient of the granulometric composition on the strength limit is determined by the formula:

$$
K_{f}=0,248 \ln N+0,99
$$

where $\mathrm{N}$ is fraction number. The correlation coefficient of the equation is 0.99 .

To clarify the influence of the thickness of the granular asphalt layer when placing, we present the data from Table 1 in a form of the relative values, assuming the strength limit for fractions with a thickness of $0.05 \mathrm{~m}$ per unit (Table 3). We denote the accepted value by the influence coefficient of the layer thickness on the strength limit $(K n)$.

Table 3: The influence of the thickness of layer on the strength limit depending on granulometric composition (in relative values)

\begin{tabular}{|c|c|c|c|c|c|}
\hline \multirow{2}{*}{$\begin{array}{c}\text { Fraction } \\
\text { number }\end{array}$} & \multirow{2}{*}{$\begin{array}{c}\text { Fraction } \\
\text { sizing } \\
\end{array}$} & \multicolumn{4}{|c|}{ Layer thickness when placing $[\mathrm{m}]$} \\
\cline { 3 - 6 } & 0,05 & 0,10 & 0,15 & 0,20 \\
\hline 1 & $5-10$ & 1,0 & 0,94 & 0,88 & 0,82 \\
\hline 2 & $10-20$ & 1,0 & 0,91 & 0,86 & 0,82 \\
\hline 3 & $5-20$ & 1,0 & 0,92 & 0,85 & 0,80 \\
\hline 4 & $20-40$ & 1,0 & 0,91 & 0,87 & 0,83 \\
\hline & $\Sigma n / n$ & 1,0 & 0,92 & 0,86 & 0,82 \\
\hline
\end{tabular}

The presented data show that the change in layer thickness when placing affects the strength limit of the placed layer regardless of the granulometric composition of the material. The dependence of the layer thickness coefficient $\mathrm{Kn}$ is shown in Fig. 4.

The numerical value of the influence coefficient of the layer thickness on the strength limit is determined by the formula:

$K_{n}=1,05 \mathrm{e}^{-1,326 h}$

where $h$ is the layer thickness, $\mathrm{m}$. The correlation coefficient of the equation is 0.99 .

Taking into account the dependencies obtained above, the value of the strength limit of the granular asphalt layer, regardless of its granulometric composition and thickness, can be determined with sufficient accuracy for practical calculations by the formula:

$\sigma_{p r}=1,785 K_{f} K_{h}, \mathrm{MPa}$

It is proved that the nominal error when determining the strength limit of the granular asphalt layer is within 5\%.

As noted previously, when choosing the parameters of machines for compacting the granular asphalt layer, it is necessary to take into account its properties [7] - [9].

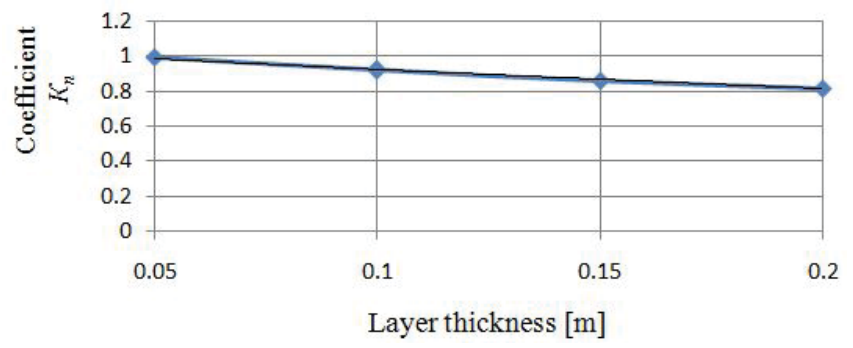

Figure 4: Dependence of the coefficient Kn on the layer thickness of granular asphalt

Istrazivanja i projektovanja za privredu ISSN 1451-4117 Journal of Applied Engineering Science Vol. 18, No. 2, 2020 
Depending on the method of placing granular asphalt, its volume weight is in the range from 1.15 to $0.6 \mathrm{t} / \mathrm{m} 3$, and when the maximum density is reached at the end of compacting it is $2.3-2.35 \mathrm{t} / \mathrm{m} 3$.During the laying process, the layer is pre-compacted, which is characterized by a pre - compacting coefficient [10] - [12]. The value of pre-compaction depends on the method of laying the material and the mechanic means that are used fora layer installation. The use of earthmoving machinery when laying granular asphalt provides a pre-compaction coefficient in the range of $0.79-0.89$, the use of crushed stone pavers increases the pre-compaction coefficient to 0.90.92. The choice of material placement method affects the parameters of the compacting machinery [13] - [15]. During the operation of compacting machinery deformation is produced in the material layer due to the relocation of material particles under load. And it promotesan increase of its density and strength. The deformation growth of the material layer depends on the thickness and granulometric composition of the applied material as well as the characteristics of the compacting equipment (line pressure of the roller and its radius) (Fig. 5).

The data of Fig. 5 show that the value of deformation and the nature of its change depends on the stress, granulometric composition and thickness of the layer. When placing a layer with a fraction of $5-10 \mathrm{~mm}$ and a thickness of up to $0.05 \mathrm{~m}$, the relationship between stress and deformation has linear character when stress is not more than 1.0 MPa. With a further increase in stress, there is a decrease in the deformation growth, which is explained by a strength improvement. When the thickness of the fraction increases owing to a decrease in the ability of the material to resist an external load, the dependence has a logarithmic character. The dependence between stress and deformation is linear with stress up to $0.5 \mathrm{MPa}$. And with a further increase in stress, the deformation growth rate slows down andthe decompression process starts at $2.0 \mathrm{MPa}$.

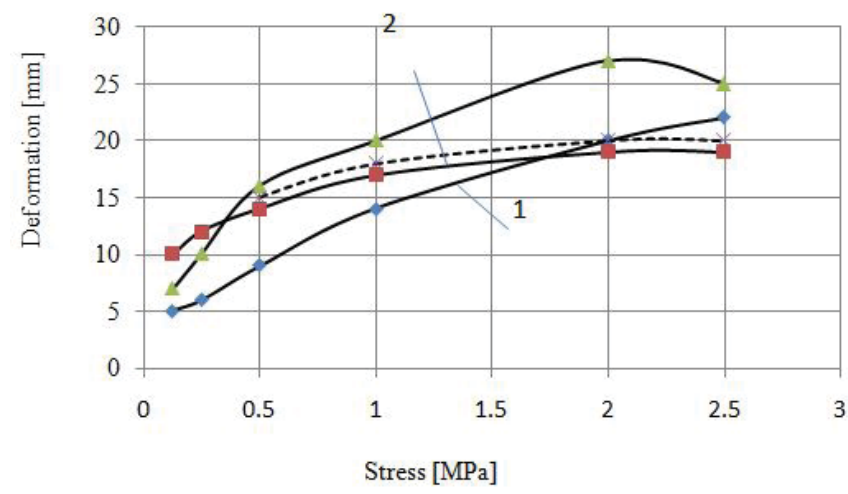

Figure 5: Deformation dependence on the stress taking into account the thickness of a layer:

1 - fraction 5-10 mm, thickness of a layer $0,05 \mathrm{~m}$;

2 fraction $5-10 \mathrm{~mm}$, thickness of a layer $0,1 \mathrm{~m}$;

3- fraction 5-20 mm, thickness of a layer $0,1 \mathrm{~m}$;

4- fraction 20-40 mm, thickness of a layer $0,1 \mathrm{~m}$
Similar processes are proceeding when compacting granular asphalt with a fraction of $5-20 \mathrm{~mm}$ and a layer thickness of $0.1 \mathrm{~m}$. The use of granular asphalt with a fraction of $20-40 \mathrm{~mm}$ when placing a layer with a thickness of $0.1 \mathrm{~m}$ is characterized by the formation of contacts between the particles of the material. It makes possible to increase the greater resistance of the material to the load action. At the initial stage of compaction under the action of the applied load there occur closer contacts between the particles. And the desired density is achieved when the load increases to a certain value. Due to the formation of a frame structure, the scope of deformation that occurs is far less than when compacting other fractions. In Table 4 the dependence of deformation on stress is presented, taking into account the granulometric composition of granular asphalt and the layer thickness.

Table 4: The dependences of deformation on stress

\begin{tabular}{|c|c|c|}
\hline \multirow{2}{*}{ Fraction [mm] } & \multicolumn{2}{|c|}{ Layer thickness [m] } \\
\cline { 2 - 3 } & 0,05 & 0,10 \\
\hline $5-10$ & $\lambda=8,16 \sigma+4,5$, & $\lambda=3,18 \ln \sigma+16,51$ \\
\hline $10-20$ & $\lambda=5,14 \sigma+8,0$, & $\lambda=4,39 \ln \sigma+26,33$ \\
\hline $5-20$ & $\lambda=3,14 \sigma+11,4$, & $\lambda=6,18 \ln \sigma+19,38$ \\
\hline $20-40$ & $\lambda=6,03 \sigma+0,65$ & $\lambda=2,32 \ln \sigma+17,71$ \\
\hline
\end{tabular}

It is known that the scope of material deformation during compaction is characterized by the dependence [5]:

$\lambda=\mathrm{f}(\sigma, t, \mathrm{~d} \sigma / \mathrm{dt})$

where $\sigma$ is the contact stress, MPa; $t$ is the load action time; $d \sigma / d t$ is the rate of change of stresses under the movable object of the equipment.

The studies have proven that at the existing operating speeds of the rollers during compaction, the rate of change of stress under the movable object of the equipment does not practically affect the development of material deformation. The load action time is determined by the speed of machinery movement during compaction and the number of passes per one track. With an increase in the number of load application to the surface of the compacting layer, the total deformation of the layer increases. And that contributes to an increase in the density of the material and, consequently, to an increase in the compacting factor. Figure 6 shows the dependences of the deformation of granular asphalt layer taking into account its thickness and granulometric composition at a constant contact stress of the roller drum (0.5 MPa).

The submitted data show that the intensive development of deformation occurs at a certain number of passes of the roller, depending on the thickness of the layer and the granulometric composition of the material. When creating a layer using a fraction of $5-20 \mathrm{~mm}$, the maximum compacting effect is achieved when the roller passes three times per one track at a given load, regardless of the thickness of the layer. Further increase in passes at 
a given load is inefficient and to increase the strength of the layer, it is necessary to use rollers with a larger mass. The value that characterizes the material compaction process is the compacting factor [16] - [18]. It was found that the dependence of the compacting factor on deformation is characterized by a linear dependence at the layer thickness of $0.05 \mathrm{~m}$ and it does not depend on the fractional composition of the material. With increasing layer thickness, the dependence is exponential [19], [20], [21]. The dependences for calculating the compacting factor on deformation are presented in Table 5.

\section{CONCLUSIONS}

1. The strength limit of the granular asphalt layer depends on the granulometric composition and thickness of the layer to be placed, which must be taken into account when choosing the parameters of compacting equipment.

2. The obtained dependences to calculate the deformation-stress relationship and the compacting factor on deformation that takes into account the particle size and the layer thickness, allow to justify the parameters of compacting equipment to ensure the required quality of the compacting of granular asphalt layer.

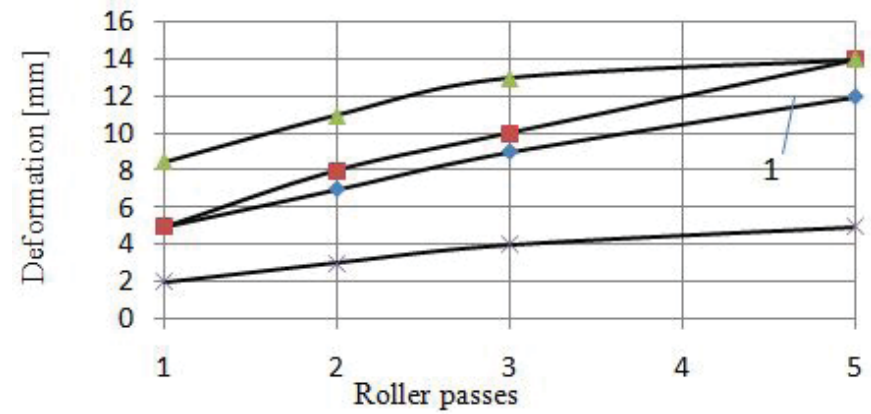

(a)

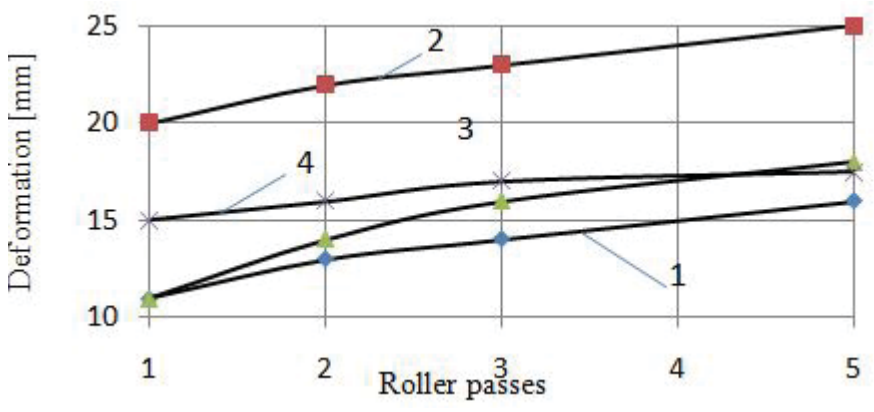

(b)

Figure 6: The dependence of deformation of granular asphalt on the number of passes:

a - layer thickness $0,05 \mathrm{~m} ; b$ - layer thickness $0,1 \mathrm{~m}$

(1- fraction 5-10 mm; 2 - 10-20; 3 - 5 -20; 4 - 20-40)

Table 5: The dependence of the compacting factor on deformation regarding the granulometric composition of the material and the layer thickness when placing

\begin{tabular}{|c|c|c|c|c|}
\hline \multirow{2}{*}{ Fraction size $[\mathrm{mm}]$} & \multicolumn{4}{|c|}{ Layer thickness [m] } \\
\cline { 2 - 5 } & \multicolumn{3}{|c|}{0,05} & \multicolumn{2}{c|}{0,10} \\
\cline { 2 - 5 } & Equation & Correlation coefficient & Equation & Correlation coefficient \\
\hline $5-10$ & $K y=0,008 \lambda+0,77$ & 0,96 & $K y=0.471 \mathrm{e}^{0,0367 \lambda}$ & 0,95 \\
\hline $10-20$ & $K y=0,011 \lambda+0,74$ & 0,95 & $K y=0.652 \mathrm{e}^{0,0124 \lambda}$ & 0,99 \\
\hline $5-20$ & $K y=0,011 \lambda+0,73$ & 0,99 & $K y=0.775 \mathrm{e}^{0,0083 \lambda}$ & 0,96 \\
\hline $20-40$ & $\mathrm{Ky}=0,033 \lambda+0,65$ & 0,965 & $K y=0.668 \mathrm{e}^{0,0186 \lambda}$ & 0,988 \\
\hline
\end{tabular}

\section{REFERENCES}

1. Zubkov A.F. The technology of construction and repair of non-rigid pavements considering the temperature conditions of asphalt concrete mixtures. Zubkov A.F., Andrianov K.A., Antonov A.I., Odnolco V.G. Tambov: Federal State-Funded Educational Establishment for Higher Education "TSTU ", 2017, 300p.

2. Permyakov V.B. The influence of operating conditions of the rollers on the intensity of compaction of asphalt mixtures. Permyakov V.B., Belyaev K.B. Stroitel'nye i dorozhnye mashiny [Construction and road equipment], 2007, no. 1, pp.19-22. - bibliogr.:p. 22 (5 names).
3. Zubkov A.F. The impact of work technology on the performance of asphalt concrete pavement. Zubkov A.F., KupriyanovR.V., Evseev E.U. Mehanizacija stroitel'stva [Construction work mechanization], 2011, no.1, (799). pp.25-29.

4. Zubkov A.F. Determining the temperature of the asphalt mix during the construction of asphalt concrete non-rigid pavement. Scientific Herald of the Voronezh State University of Architecture and Civil Engineering / A.F. Zubkov, R.V. Kupriyanov, V.A. Luzgachev. Construction and Architecture. 2016, no. 1 (29). pp. 63-74.

5. Kharkhuta N.Y. Theory questions of compaction of pavings. Uplotnenie zemljanogo polotna i dorozhny hodezhd [Compacting of roadbed and pavement], Soyuzdornii, Moscow, 1980. pp.64-71. 
6. Alexikov S.V. Comparative assessment of the uniformity of compaction of asphalt concrete pavements of urban roads under various operating conditions of rollers. Alexikov S.V., Ermilov A.A. Nauchnyj vestnik VGASU. Series Construction and architecture. 2014, is. 1 (33). Pp.45-53.

7. Piletsky M.E. Investigation of bitumen-mineral mixture used for patching of pavements by jet-injection method. Piletsky M.E., Zubkov A.F., Andrianov K.A. Stroitel'nye materialy [Construction materials].2017, no. 6.pp. 19-23.

8. Piletsky M.E. Characterization of a bitumen-mineral mixture when placing into a pothole of a pavement by the jet-injection method. Piletsky M.E., Zubkov A.F., Andrianov K.A. Privolzhskij nauchnyj zhurnal, Nizhny Novgorod State University of Architecture and Civil Engineering (NNSAGU), no. 2, 2018, pp.70-77.

9. Piletsky M.E. Non-rigid coating patching by injection-jet method. Piletsky M.E. Didrikh I.V., Zubkov A.F., Tugolukov E.N. Nauchnyj zhurnal stroitel'stvaiarhitektury VGTU [Scientific Journal of Construction and Architecture] (Voronezh). 2018, no. 1 (49), pp.80-88.

10. Piletsky, M.E. Pothole maintenance of non-rigid paving surfaces using the injection flow method. Piletsky M.E., Didrikh I.V., Zubkov A.F Russian Journal of Building Construction and Architecture 2018, no. 2 (38). pp.47-87.

11. Nosov S.V. Development of compaction technologies for road asphalt mixes and soils based on the development of their rheology. Doc. diss: 05.23.11. Nosov S.V. Voronezh, 2013, 366p.

12. Permyakov V.B. Justification of the contact pressure magnitude for compaction of asphalt mixtures. Permyakov V.B., Zakharenko A.V. Stroitel'nye i dorozhnye mashiny [Construction and road equipment], 1989, no. 5, pp.12-13.

13. Aleksikov, S.V. Comparative assessment of uniformity of compaction of asphalt concrete surfaces of city roads at various operating modes of compactors .S.V. Aleksikov, A.A. Yermilov. Scientific Herald of the Voronezh State University of Architecture and Civil Engineering. Construction and Architecture. 2014, Issue 4 (24). pp. 48-57.
14. Asphaltic compaction methods // Constr West. 1967, 22, no.1. pp. 40-42.

15. Asphalt paving design guide. Asphalt Paving Association of lowa.1990, $125 \mathrm{p}$.

16. Asphalt pavement design guide for Low-Volume Roads and Parking Lots .2014, 28 p.

17. Kuprianow, R. Analiza zmian temperatury ukladanych warstw $\mathrm{z}$ mieszanek mineralno-asfaltowych w strefie spoiny podluznej / R. Kuprianow, K. Andrianow, A. Zubkow, A. Plewa // Budownictwa i Inzynierii Srodowiska. 2015, no.3, pp.113-117.

18. Plewa, A. The effect of modifying additives on the consistency and properties of bitumen binders. A. Plewa, P.S. Belyaev, K.A. Andrianov, A.F. Zubkov, V.A. Frolov. Advanced Materials and Technologies. 2016, no. 4, pp. 35-40.

19. Piletsky, M.E. Influence of the load-carrying capacity of vehicles when performing repair works of road pavements by means of the jet-injection method. Piletsky M.E., Andrianov K.A., Zubkov A.F. Russian Journal of Building Construction and Architecture. 2020, no. 1 (45), pp. 42-54.

20. Senibabnov, S.A. Analysis of normative documentation on the calculation of the strength characteristics of non-rigid road pavement for the permissible elastic deformation. Senibabnov S.A., Andrianov K.A., Zubkov A.F. Russian Journal of Building Construction and Architecture. 2020, no.1 (45), pp. 66-84.

21. A. Kolesnikov, T.Tolmacheva [2019]. Ways to Minimize Volume (Weight) and Increase the Bearing Capacity of Rigid Pavement. Civil Engineering Journal. 5(11), 2495-2501

22. Kapustin, V., Khaustov, V., \& Kapustin, V. K. [2017]. Researches of soilses secondary consolidation. Journal of Applied Engineering Science, 15(3), 339344.

23. Gennadyevich, Y. S., Pakhomova, E. G., \& Olegovna, D. K. [2019]. Reliability of RC frame-braced systems in dangerous geological conditions. Journal of Applied Engineering Science, 17(2), 245-250. 